\title{
ERCC1 polymorphisms as prognostic markers in T4 breast cancer patients treated with platinum-based chemotherapy
}

Grazia Palomba ${ }^{1}$, Francesco Atzori ${ }^{2}$, Mario Budroni ${ }^{3}$, MariaNeve Ombra ${ }^{4}$, Antonio Cossu ${ }^{5}$, MariaCristina Sini ${ }^{1}$, Valeria Pusceddu ${ }^{2}$, Bruno Massidda ${ }^{2}$, Barbara Frau ${ }^{2}$, Francesca Notari ${ }^{2}$, MariaTeresa lonta ${ }^{2+}$ and Giuseppe Palmieri ${ }^{{ }^{*+}+}$

\begin{abstract}
Background: Polymorphisms in the excision repair cross-complimentary group 1 (ERCC1) gene have been involved in the prognosis of various cancers. In the present study, we evaluated the prognostic role of the two most common ERCC1 polymorphisms in patients with T4 breast cancer receiving platinum-based chemotherapy.

Methods: A total of 47 patients with T4 breast cancer undergoing treatment with a platinum-based regimen were collected and followed up (median 159 months; range, 42-239 months). ERCC1 C8092A (rs3212986) and T19007C (rs11615) polymorphisms were genotyped, using an automated sequencing approach. The same series was screened for BRCA1/2 mutations by DHPLC analysis and DNA sequencing.

Results: Among the tested patients, 16 (34\%) and 25 (53\%) presented the 8092A (homo-zygosity A/A or heterozygosity A/C) and the 19007C (homozygosity C/C or heterozygosity C/T) genotypes, respectively. The 8092A and 19007C genotypes in ERCC1 were significantly associated with overall survival in T4 breast cancer patients treated with chemotherapy containing platinum ( $\mathrm{p}$-values $=0.036$ and 0.004 , respectively). Univariate and multivariate Cox regression analyses showed that combination of 8092A and 19007 C genotypes acts as a significant prognostic factor in women with T4 breast cancer receiving platinum-based chemotherapy ( $p$-values $=0.022$ and 0.049 , respectively). Two (4.3\%) out of 47 cases were found to carry BRCA1/2 mutations; they presented the highest overall survival rates into the series.
\end{abstract}

Conclusions: The ERCC1 8092A and 19007 C genotypes or their combination may predict a favorable prognosis in T4 breast cancer patients undergoing a platinum-based treatment. Further large-scale, prospective studies are needed to validate our findings.

Keywords: T4 breast cancer, Genetic polymorphism, Platinum-based chemoterapy, Prognosis

\section{Introduction}

Breast cancer remains the most frequent tumor and the leading cause of cancer-related death among the female population worldwide [1].

Locally advanced breast cancer (LABC) represents a heterogeneous group of diseases associated with a poor prognosis. According to the International Union Against Cancer (UICC)/American Joint Committee on Cancer (AJCC) TNM staging system, primary breast cancers with

\footnotetext{
* Correspondence: gpalmieri@yahoo.com

${ }^{\dagger}$ Equal contributors

${ }^{1}$ Institute of Biomolecular Chemistry (ICB), National Research Council (CNR),

Traversa La Crucca, 3 - Località Baldinca Li Punti, 07100 Sassari, (SS), Italy
}

Full list of author information is available at the end of the article extension to the skin, with or without lymph node involvement, and without distant metastases (T4 N0-2 M0), may be included in stage III and considered as LABC [2].

Overall, patients with LABC - including cases presenting an inflammatory disease and, mostly, those carrying a triple-negative breast cancer - are particularly responsive to DNA-damaging agents such as platinum compounds; for this reason, platinum-based chemotherapy is frequently used as neoadjuvant treatment in such disease types [3-6]. The cytotoxic effect of platinum drugs is ascribed to the formation of bulky platinum-DNA adducts, which block replication and transcription through inter-strand cross-link of the two DNA strands, leading 
to cancer cell death. These adducts are recognized and removed, with subsequent repair of the inter-strand cross-links in DNA, by factors of the nucleotide excision repair (NER) pathway [7]. Recent published data have revealed that single nucleotide polymorphisms (SNPs) in DNA repair genes may represent an underlying molecular mechanism that explains inter-individual variation in DNA repair capacity [7].

The excision repair cross-complementing 1 (ERCC1) is one of the key effector of the NER pathway. This enzyme acts as a DNA damage repair gene, which is essential for the removal of platinum-DNA adducts as well as for recognition and correction of DNA damage [8]. Functional variants in genes involved in the DNA repair pathway may be important determinants of platinum response [9]. Therefore, ERCC1 mRNA and protein expression level or ERCC1 gene polymorphisms may be used to predict the outcome in patients receiving platinumbased chemotherapy $[10,11]$.

C8092A (rs3212986) and T19007C (rs11615) are two common polymorphisms in ERCC1 gene. The C8092A polymorphism is located in the 3'untranslated region of the gene and may affect ERCC1 messenger RNA stability. The synonymous T19007C polymorphism at codon 118 (Asn118Asn) converting a common codon usage (AAC) to an infrequent one (AAT), both coding for asparagine, has been proposed to impair ERCC1 translation and to affect the response to chemotherapy [12].

In recent years, many studies focused on the association between clinical behavior of different types of cancer and specific SNPs in genes involved in DNA repair, including genes of the NER pathway. Although controversial results have been reported for association between polymorphisms of ERCC1 and cancer outcome (see below), increasing and more consistent evidence suggest a relationship between the level of ERCC1 expression and the response to chemotherapy. Higher mRNA levels of ERCC1 are associated with lack of platinum response in advanced lung [13,14], ovarian [15], bladder [16], and gastrointestinal [17-19] cancers. Consequently, lower ERCC1 mRNA levels have been found consistently associated with an improved tumor response using platinum-containing compounds $[8,14,17]$.

Polymorphisms in ERCC1 gene have been studied extensively, with controversial results. A study indicates that the codon $118 \mathrm{C}>\mathrm{T}$ polymorphism was not associated with clinical outcome in women with stage III ovarian cancer, whereas the C8092A polymorphism was an independent predictor of progression-free survival and overall survival (OS) in the same series of patients [20]. In contrast to this findings, additional reports indicated that the $\mathrm{C} / \mathrm{C}$ genotype at codon 118 of ERCC1 expression may predict the response to platinum in either the same type of ovarian cancer [15] or other malignancies
[12,21]. Overall, the T19007C polymorphism showed a controversial association with clinical outcome (in terms of either tumor response or OS) among different types of cancers [22-24]. The C8092A polymorphism was instead associated with a more favorable outcome in head and neck squamous cell carcinoma and advanced non small cell lung cancer patients [25,26]. Finally, the accumulated evidence provided by a meta-analysis of the literature clearly indicated that ERCC1 T19007C and C8092A polymorphisms might not act as risk factors for cancer [27].

There are differences in survival among patients who begin treatment in a similar disease status and genetic factors may influence the effectiveness of therapy. For this reason the availability of new biomarkers that can accurately predict the prognosis and patient response to the treatment is a central issue to improve therapeutic strategies.

The aim of the present study was to investigate whether the ERCC1 $19007 \mathrm{C}>\mathrm{T}$ and $8092 \mathrm{C}>\mathrm{A}$ polymorphisms may influence the clinical outcome in response to treatment with platinum within a well-characterized cohort of patients with $\mathrm{T} 4$ breast carcinoma and long follow-up evaluation. Since germline mutations in $B R C A 1$ and, to a less extent, BRCA2 genes have been found in a variable proportion (ranging from $10 \%$ to $30 \%$ ) of patients with LABC or, mostly, triple-negative breast cancer [28], and such gene dysfunctions seem to be associated with prognosis [29], we also evaluated the prevalence of BRCA1-2 mutations in our series.

\section{Materials and methods \\ Samples}

Germline DNA samples of 47 consecutive patients with T4 breast cancer [12 (26\%) of them classified as inflammatory breast cancer (T4d-IBC)] were included into the study. Cases were enrolled between 1995 and 2004, and observed up to July 2013 for an overall median of 161 months (range, 13-242 months). Patients were assessed by physical examination and mammography, confirmed via core-needle biopsy. All patients completed a treatment plan including neoadjuvant platinum-based chemotherapy, surgery, radiation therapy, adjuvant chemotherapy, and hormone therapy, when indicated (see below). All patients were of Sardinian origin; the median age at diagnosis was 51 years (range 33-67 years). Patients' characteristics are summarized in Table 1.

The study was approved by the Review Board at the University of Cagliari (Prot. 102/1996). A written informed consent was obtained for using tissue specimens in molecular analyses.

\section{Treatment plan}

All 47 patients were treated with primary chemotherapy using PEV [cisplatin, epirubicin, vinorelbine; $\mathrm{N}=42$ (89\%)] 
Table 1 Patients' characteristics and clinical features

\begin{tabular}{|c|c|c|}
\hline Characteristics & Patients $(N=47)$ & $\%$ \\
\hline \multicolumn{3}{|l|}{ Age (year) } \\
\hline \multicolumn{3}{|l|}{ Median 51 (range 33-67) } \\
\hline$<50$ & 21 & 45 \\
\hline$>50$ & 26 & 55 \\
\hline \multicolumn{3}{|l|}{ Histologic type } \\
\hline Ductal carcinoma & 29 & 62 \\
\hline Lobular carcinoma & 10 & 21 \\
\hline Other & 1 & 2 \\
\hline Unknown & 7 & 15 \\
\hline \multicolumn{3}{|l|}{ Tumor grading } \\
\hline G2 & 33 & 70 \\
\hline G3 & 14 & 30 \\
\hline \multicolumn{3}{|l|}{ Tumor extent } \\
\hline $\mathrm{T} 4 \mathrm{a}, \mathrm{b}, \mathrm{c}$ & 35 & 74 \\
\hline $\mathrm{T} 4 \mathrm{~d}$ & 12 & 26 \\
\hline \multicolumn{3}{|c|}{ Lymph node involvement } \\
\hline NO & 6 & 13 \\
\hline $\mathrm{N}+$ & 41 & 87 \\
\hline \multicolumn{3}{|l|}{ ER/PgR status } \\
\hline ER positive/ER negative & $23 / 24$ & $49 / 51$ \\
\hline PR positive/PR negative & $16 / 31$ & $34 / 66$ \\
\hline \multicolumn{3}{|l|}{ HER2 status } \\
\hline HER-2 positive & 13 & 28 \\
\hline HER-2 negative & 34 & 72 \\
\hline \multicolumn{3}{|l|}{ Triple-negative status } \\
\hline Present & 19 & 40 \\
\hline Absent & 28 & 60 \\
\hline \multicolumn{3}{|l|}{ Proliferative index } \\
\hline Ki67 positive & 24 & 51 \\
\hline Ki67 negative & 23 & 49 \\
\hline
\end{tabular}

or PE-TXT [cisplatin, epirubicin, docetaxel; $\mathrm{N}=5(11 \%)$ ]. After completing the neoadjuvant chemotherapy, patients underwent breast-conserving surgery $(17 / 47 ; 36 \%)$ or radical mastectomy $(30 / 47 ; 64 \%)$. Postoperative adjuvant chemotherapy consisted of six cycles of CMF (cyclophosphamide, methotrexate, fluorouracil). Locoregional radiotherapy was performed during the fourth course of CMF. After completing adjuvant chemotherapy, patients with hormone receptor-positive tumours received tamoxifen for 5 years.

Clinical evaluations were performed every 3 months for 2 years and every 6 months thereafter. Instrumental examinations (e.g., mammography, liver ultrasound, chest X-ray, bone scan, and echocardiogram) were performed every 6 months for the first 2 years, and every 12 months thereafter.

\section{Genetic analysis}

Genomic DNA from all patients was isolated from peripheral blood nucleated cells, using standard methods, and then screened for the $\mathrm{C}>\mathrm{A}$ and $\mathrm{C}>\mathrm{T}$ polymorphisms at positions 8092 and 19007, respectively, of the $E R C C 1$ gene, using an automated direct sequencing approach. Primers for polymerase chain reaction (PCR) assays and protocols for PCR-based amplification have been previously described [30].

The entire coding sequences and intron-exon boundaries of the BRCA1 and BRCA2 genes were screened for germline mutations among all patients from our series. Mutation analysis was performed by denaturing highperformance liquid chromatography (DHPLC), followed by automated sequencing, as we previously reported [31,32]. Briefly, DHPLC analysis was carried out with the Wave ${ }^{\circ}$ nucleic acid fragment analysis system (Transgenomic, Santa Clara, CA). Suspected variants are visualized as a characteristic pattern of peaks corresponding to the mixture of homo- and heteroduplex formed when wild-type and mutant DNA are hybridized. Abnormal PCR products identified by DHPLC analysis were directly sequenced using an automated fluorescence-cycle sequencer (ABIPRISM 3130, Life Technologies/ThermoFisher Scientific, Waltham, MA, USA).

\section{Statistical analysis}

Odds ratios of carrying the ERCC1 19007C > T and $8092 \mathrm{C}>$ A polymorphisms were estimated by the logistic regression model and reported with 95\% confidence interval $(95 \% \mathrm{CI})$. Analyses were performed with the statistical package SPSS/7.5 for Windows.

\section{Results}

\section{Patient characteristics and treatments}

Forty-seven patients with diagnosis of T4 breast carcinoma (T4-N0/2-M0, according to the TNM classification by Sobin et al. [33]) were included into the study. Considering the disease staging system [33], all cases from our series were classified with the highest stage of nonmetastatic disease (Stage IIIB). Among them, 19 (40\%) patients presented the subtype of triple-negative breast cancer, with the characteristics of estrogen receptor (ER) negative, progesterone receptor (PR) negative, and human epidermal growth factor receptor-2 (HER-2) negative (Table 1). All the patients received platinum-based chemotherapy as the neoadjuvant treatment: nearly all of them (89\%; see Methods) received PEV treatment. After surgery, adjuvant treatment included CMF chemotherapy for six cycles and locoregional radiotherapy (see Methods).

\section{C9082A and T19007C polymorphisms in ERCC1}

Genomic DNA samples were extracted from peripheral blood mononuclear cells and single nucleotide 
polymorphisms, C8092A (rs3212986) and T19007C (rs11615), in the ERCC1 gene were analyzed using an automated sequencing approach.

For C8092A, 16 (34\%) patients presented the A genotype (3 AA, $13 \mathrm{AC}$ ), whereas $31(66 \%)$ cases presented the C genotype (CC). For T19007C, the C (12 CC, $13 \mathrm{CT})$ and the T (TT) genotypes were found in 25 (53\%) and 22 (47\%) patients, respectively. Both distributions were in Hardy-Weinberg equilibrium. Considering the two polymorphisms the distribution of AC, AT, CC and CT genotypes was $25.5 \%, 8.5 \%, 28 \%$, and $38 \%$, respectively.

\section{BRCA mutation analysis}

The germline DNA samples from the T4 breast carcinoma patients of the present study was analyzed for mutations in both the BRCA1 and BRCA2 genes, as previously described [31,32]. Among the 47 cases of the series, two germline coding region mutations of known functional significance in either $B R C A 1$ or $B R C A 2$ were detected in two (4.3\%) patients. Both mutations, BRCA1 (2CA) 916delTT and BRCA2 3951del3insAT, were absent in normal genomic DNA from 103 unrelated healthy individuals (corresponding to 206 control chromosomes) and were classified as disease-causing variants due to their predicted effects on proteins.

\section{Survival analysis}

As of July 2013, 18 (38\%) patients have died due to disease, with the median overall survival of the whole sample being 108 months and the median follow-up of live patients of 153 months.

According to the C8092A polymorphism status, the median OS was significantly higher for patients carrying the $\mathrm{A}(\mathrm{AA}+\mathrm{AC})$ genotype as compared to those with the $C(C C)$ genotype (123.5 vs.101.6 months; $\mathrm{p}=0.036)$. Analogously, a significantly strong association between the T19007C polymorphism and overall survival was observed; the median OS was 131 months for carriers of the $\mathrm{C}(\mathrm{CC}+\mathrm{CT})$ genotypes and 66.5 months for TT homozygotes $(\mathrm{p}=0.004)$ (Table $2 \mathrm{~A})$. When the combination

Table 2 Logistic regression analysis for overall survival and ERCC1 polymorphisms

\begin{tabular}{lllll}
\hline A & & & & \\
& Odds ratio & $95 \%$ Cl lower & 95\% Cl upper & p-value \\
\hline C8092A & $\mathbf{1 . 9 5 7}$ & $\mathbf{1 . 2 7 6}$ & $\mathbf{5 . 6 7 5}$ & $\mathbf{0 . 0 3 6}$ \\
T19007C & $\mathbf{3 . 8 7 5}$ & $\mathbf{1 . 8 6 5}$ & $\mathbf{1 8 . 8 5 1}$ & $\mathbf{0 . 0 0 4}$ \\
\hline B & & & & \\
& Odds ratio & $\mathbf{9 5 \%}$ Cl lower & $\mathbf{9 5 \% ~ C l ~ u p p e r}$ & p-value \\
\hline C8092 + T19007 & 2.479 & 0.538 & 11.421 & 0.244 \\
8092A + 19007C & $\mathbf{5 . 6 0 9}$ & $\mathbf{1 . 2 7 8}$ & $\mathbf{2 4 . 6 2 2}$ & $\mathbf{0 . 0 2 2}$ \\
\hline
\end{tabular}

Single (A) or combined (B) ERCC1 genotypes have been considered for statistical analysis. Significant associations are in bold. $\mathrm{Cl}$, confidence interval. of both ERCC1 polymorphisms were included in univariate analysis, carriers of the combined 8092A/19007C genotype presented an overall survival significantly longer than that of patients carrying the combined C8092/ T19007 genotype (143.5 vs. 91.7 months; $\mathrm{p}$-value $=0.022$ ) (Table 2B). No association between T19007 or C8092A ERCC1 polymorphisms and age at diagnosis, tumor grade, histology, menopausal condition was detected (not shown).

Using the Kaplan-Meier method, survival curves indicated that patients carrying either $8092 \mathrm{~A}$ or $19007 \mathrm{C}$ genotypes presented a statistically-significant better overall survival in comparison with those carrying the remaining other genotypes ( $p<0.001$ for both 8092A and 19007C genotypes; Figure 1).

Using the Cox model adjusted according to age at diagnosis for a multivariate analysis, pathological response to primary chemotherapy and both two ERCC1 polymorphisms remained the only parameters with a significant impact on prognosis in our series of breast cancer patients; no other association with overall survival was observed for the remaining variables (Table 3A). Again, the combined 8092A/19007C genotype remained a statistically independent factor predicting a more favourable prognosis in multivariate logistic regression $(p=0.049)$ (Table 3B).

Finally, it is worthy to notice that the two patients who carried a $B R C A 1$ or $B R C A 2$ germline mutation presented the highest overall survival rates of the series (238 and 195 months, respectively).

\section{Discussion}

In this study, two single nucleotide polymorphisms, C8092A and T19007C, in ERCC1 gene were retrospectively evaluated for their association with the clinical behavior in a group of $\mathrm{T} 4$ breast carcinoma patients of Sardinian origin, receiving platinum-based chemotherapy. We have demonstrated that two genotypes within such polymorphisms have a role as independent prognostic factors for a more favorable clinical outcome in this subset of patients.

In breast cancer, the choice of cytotoxic chemotherapy is generally based on tumor extent and disease features. Identification of surrogate markers as potential predictive factors will be useful to improve the clinical management of breast cancer patients (i.e., to identify which subset of patients is expected to show either a response or a lack of response to a particular therapy). Various attempts have been made to improve the survival of patients with T4 breast carcinoma, for instance, discovering novel predictive biomarkers to identify patients who may really benefit from platinum-based chemotherapy.

Platinum agents such as cisplatin and carboplatin are DNA-damaging agents with activity in breast cancer, 

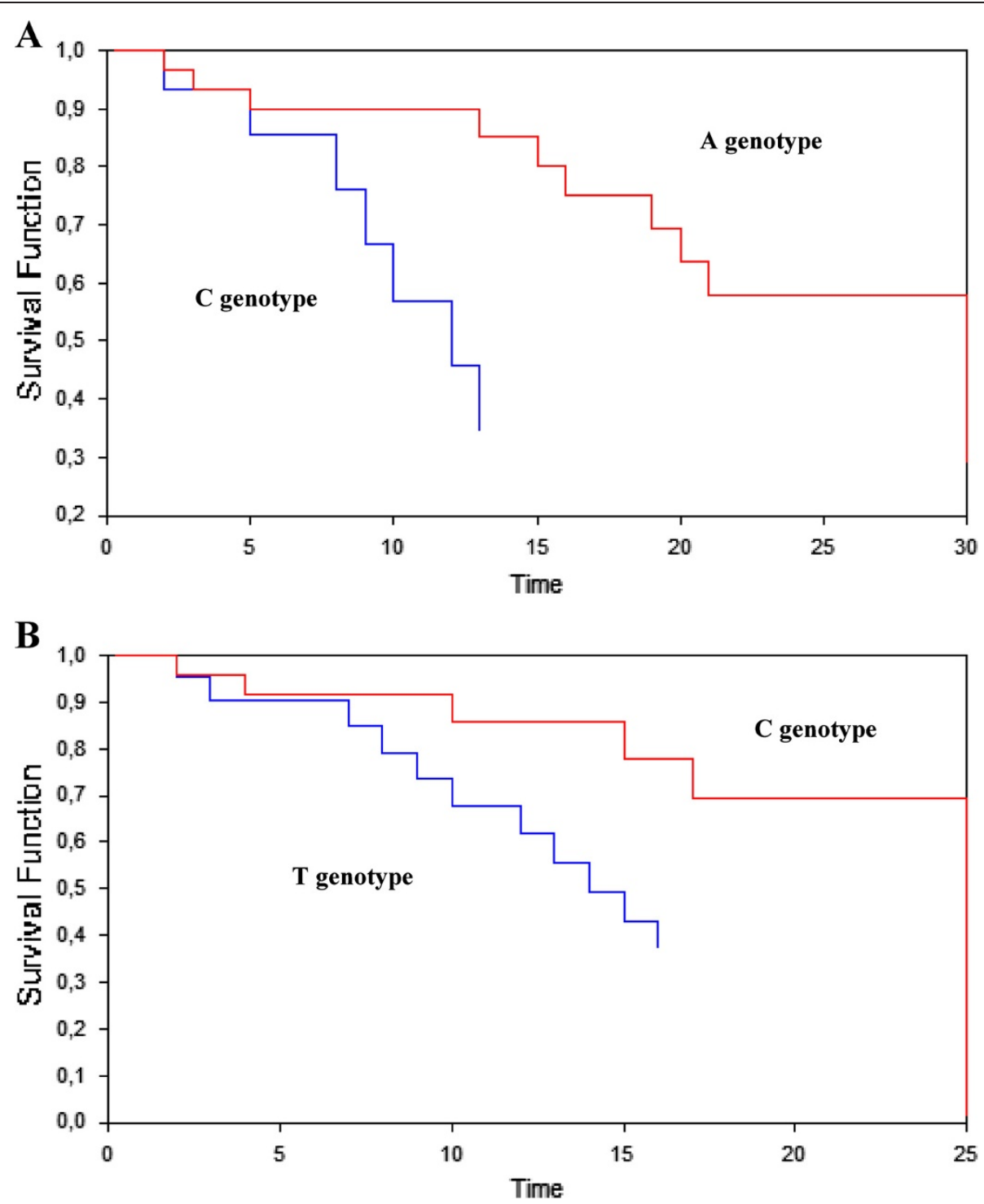

Figure 1 Kaplan-Meier curves for ERCC1 C8092A (A) and T19007C (B) polymorphisms in T4 breast cancer patients.

particularly in the triple negative subgroup [34-36]. In neoadjuvant strategies for the treatment of locally advanced breast cancer ( $\mathrm{LABC}$ ), the utility of platinum agents in addition to standard chemotherapy is yet to be completely clarified. Therefore, identification of factors relevant to better predict the clinical outcome in response to platinum agents may be helpful in achieving an absolute advantage for the management of the LABC disease.

ERCC1 (excision repair cross complementation group 1) can recognize and correct DNA damage through a DNA strand incision and homologous recombination mechanisms [8,30]. High ERCC1 expression has been demonstrated to be associated with resistance to platinum-based chemotherapy and worse prognosis in cancer patients $[20,37,38]$. To this aim, we here assessed that the ERCC1 gene polymorphisms may play an analogous clinical role as predictive and prognostic factor among patients with $\mathrm{T} 4$ breast cancer receiving platinumbased therapy.

Several clinical studies have explored the role of ERCC1 as a marker for platinum sensitivity in cancer patients. For example, various studies have focused on the relationship between ERCC1 polymorphisms and prognosis for the treatment with platinum agents in colorectal cancer patients. Sequence variations in ERCC1 gene may indeed alter the DNA repair capacity, making biologically plausible to assume that polymorphisms of this gene might have functional significance in cancer.

In our study, the ERCC1 polymorphisms were determined using an automated sequencing method. For C8092A polymorphism, the A genotype was significantly 
Table 3 Cox proportional hazard model for multivariate analysis of different parameters

\begin{tabular}{|c|c|c|c|c|}
\hline \multicolumn{5}{|l|}{ A } \\
\hline Characteristics & p-value & Odds ratio & 95\% Cl lower & 95\% Cl upper \\
\hline Menopausal status & 0.176 & 0.854 & 0.177 & 1.465 \\
\hline Age at diagnosis & 0.283 & 0.916 & 0.110 & 1.906 \\
\hline ER & 0.454 & 0.809 & 0.191 & 2.233 \\
\hline HER-2 & 0.483 & 0.971 & 0.117 & 2.602 \\
\hline Triple negative status & 0.128 & 1.006 & 0.213 & 2.834 \\
\hline Tumor grading & 0.982 & 0.968 & 0.194 & 4.075 \\
\hline Lymph node $(\mathrm{N}+)$ & 0.644 & 0.873 & 0.125 & 3.614 \\
\hline Pathological response to primary chemotherapy & 0.043 & 5.274 & 1.388 & 26.173 \\
\hline $8092 A$ & 0.048 & 2.690 & 1.091 & 9.053 \\
\hline $19007 C$ & 0.031 & 4.177 & 1.226 & 23.131 \\
\hline \multicolumn{5}{|l|}{ B } \\
\hline Characteristics & $p$-value & Odds ratio & 95\% Cl lower & 95\% Cl upper \\
\hline C8092 + T19007 & 0.430 & 1.266 & 0.334 & 3.231 \\
\hline $8092 A+19007 C$ & 0.049 & 4.377 & 1.031 & 23.112 \\
\hline ER & 0.332 & 0.793 & 0.143 & 2.655 \\
\hline$P R$ & 0.459 & 1.127 & 0.178 & 4.117 \\
\hline HER-2 & 0.139 & 0.699 & 0.166 & 1.223 \\
\hline Ki67 & 0.073 & 0.222 & 0.053 & 1.081 \\
\hline Pathological response to primary chemotherapy & 0.051 & 0.565 & 0.136 & 1.377 \\
\hline
\end{tabular}

Single (A) or combined (B) ERCC1 genotypes have been considered for statistical analysis. Significant associations are in bold. Cl, confidence interval.

associated with overall survival of T4 breast cancer patients treated with chemotherapy containing platinum compounds (OR 1.957, 95\%CI 1.276- 5.675; $\mathrm{p}$ value $=$ 0.036). Analogously, the $\mathrm{C}$ genotype of T19007C polymorphism was significantly associated with overall survival in the same series (OR 3.875, 95\%CI 1.865-18.851; $\mathrm{p}$-value $=0.004)$. Univariate and multivariate Cox regression analyses showed that the combination of the 8092A and $19007 \mathrm{C}$ genotypes acts as an independent prognostic factor in this group of T4 breast cancer patients receiving platinum-based chemotherapy ( $\mathrm{p}$-values $=0.022$ and 0.049 , respectively).

The precise mechanism by which the C8092A polymorphism is positively associated with a favorable prognosis remains indeterminate, as there are no direct functional data available for this polymorphism. Since the SNP is located at the 3'untranslated region (3'UTR) which can be controlled by regulatory proteins and micro-RNAs, the C8092A polymorphism in the $3^{\prime}$ UTR region could however affect the stability and, thus, translation rates of the corresponding mRNA, finally influencing the expression levels of the ERCC1 protein into the cells. On the other side, the synonymous T19007C polymorphism at codon 118 (Asn118Asn) is a common silent substitution, and the exact function of Asn118Asn has not been clarified yet. Again, it could also affect the stability of mRNA or influence the rates of translation by converting a high usage codon to a low usage one. Alternatively, it could be biologically plausible that this correlation may be mediated by linkage disequilibrium with other potentially functional single-nucleotide polymorphisms.

The entire group of 47 patients was then screened for germline mutations in $B R C A 1 / 2$ genes and, of note, two (4.3\%) carriers of $B R C A 1 / 2$ mutations presented the highest rates of overall survival within the series. No statistical analysis was carried out due to such a limited number of $B R C A$-mutated cases. The lack of functional BRCA (mainly, BRCA1) can lead to increased sensitivity of the tumor cells to molecular damage, demonstrating that BRCA mutations represent a predictive marker of response to DNA-damaging chemotherapies [39-41]. Certainly, the reduced ability to repair damaged DNA along with the impairment of the function of the ERCC1 protein, due to the presence of the combined 8092A and 19007C genotypes, may have contributed to determine the longest overall survival in such a limited subset of patients from our series.

Several limitations of this study should be addressed. Firstly, the sample size may limit the statistical power of our study (findings need further replication in a larger patients' collection); next, the belonging of cases to a 
particular, genetically-homogeneous population (ethnicity may interfere with observed associations in multifactorial diseases; extension of the study in other geographical areas with general, genetically-heterogeneous populations is also recommended). However, to our knowledge, this is the first study clearly demonstrating that polymorphisms in $E R C C 1$ gene are significantly associated with overall survival in patients with $\mathrm{T} 4$ breast cancer receiving platinumbased treatment. Overall, this seems to suggest that such sequence variations could be considered as novel prognostic biomarkers for the management of the T4 breast cancer patients.

\begin{abstract}
Abbreviations
DHPLC: Denaturing high-performance liquid chromatography; ER: Estrogen receptor; ERCC1: Excision repair cross-complementing 1; HER-2: Human epidermal growth factor receptor-2; LABC: Locally advanced breast cancer; NER: Nucleotide excision repair; OS: Overall survival; PR: Progesterone receptor; SNP: Single nucleotide polymorphism.
\end{abstract}

\section{Competing interests}

The authors declare that they have no competing interest.

\section{Authors' contributions}

GrP, performed DNA sequencing, helped to draft the manuscript; FA, performed data interpretation; $\mathrm{MB}$, performed statistical analysis; MO, performed data analysis, helped to draft the manuscript; AC, performed quality control of pathological data; MS, contributed to mutation analysis; VP, $\mathrm{BM}, \mathrm{BF}$, and FN, participated in patients' collection and data acquisition; MI, participated into the study design and data discussion; GP, conceived of the study and participated in its design and coordination, helped to draft the manuscript. All authors read and approved the final manuscript.

\section{Acknowledgments}

Authors are grateful to patients for their important contribution to this study. Work was partially supported by the Sardinia Regional Government (Regione Autonoma della Sardegna).

\section{Author details}

${ }^{1}$ Institute of Biomolecular Chemistry (ICB), National Research Council (CNR), Traversa La Crucca, 3 - Località Baldinca Li Punti, 07100 Sassari, (SS), Italy. ${ }^{2}$ Department of Medical Oncology, Hospital-University of Cagliari, Cagliari, Italy. ${ }^{3}$ Epidemiology Unit, Azienda Sanitaria Locale 1, Sassari, Italy. ${ }^{4}$ Institute of Food Science (ISA), National Research Council (CNR), Avellino, Italy. ${ }^{5}$ Institute of Pathology, Azienda Ospedaliero Universitaria, Sassari, Italy.

Received: 2 August 2014 Accepted: 19 September 2014

Published online: 25 September 2014

\section{References}

1. Jemal A, Bray F, Center MM, Ferlay J, Ward E, Forman D: Global cancer statistics. CA Cancer J Clin 2011, 61:69-90.

2. Singletary SE, Allred C, Ashley P, Bassett LW, Berry D, Bland KI, Borgen PI, Clark G, Edge SB, Hayes DF, Hughes LL, Hutter RV, Morrow M, Page D, Recht A, Theriault RL, Thor A, Weaver DL, Wieand HS, Greene FL: Revision of the American Joint Committee on Cancer staging system for breast cancer. J Clin Oncol 2002, 20:3628-3636.

3. Aapro MS: Neoadjuvant therapy in breast cancer: can we define its role? Oncologist 2001, 6(Suppl. 3):36-39.

4. Silver DP, Richardson AL, Eklund AC, Wang ZC, Szallasi Z, Li Q, Juul N, Leong CO, Calogrias D, Buraimoh A, Fatima A, Gelman RS, Ryan PD, Tung NM, De Nicolo A, Ganesan S, Miron A, Colin C, Sgroi DC, Ellisen LW, Winer EP, Garber JE: Efficacy of neoadjuvant cisplatin in triple negative breast cancer. J Clin Oncol 2010, 28:1145-1153.

5. Torrisi R, Cardillo A, Cancello G, Dellapasqua S, Balduzzi A, Ghisini R, Luini A, Veronesi P, Viale G, Goldhirsch A, Colleoni M: Phase II trial of combination of pegylated liposomal doxorubicin, cisplatin, and infusional 5-fluorouracil (CCF) plus trastuzumab as preoperative treatment for locally advanced and inflammatory breast cancer. Clin Breast Cancer 2010, 10:483-488.

6. Hurley J, Reis IM, Rodgers SE, Gomez-Fernandez C, Wright J, Leone JP, Larrieu R, Pegram MD: The use of neoadjuvant platinum-based chemotherapy in locally advanced breast cancer that is triple negative: retrospective analysis of 144 patients. Breast Cancer Res Treat 2013, 138:783-794.

7. Goode EL, Ulrich CM, Potter JD: Polymorphisms in DNA repair genes and associations with cancer risk. Cancer Epidemiol Biomarkers Prev 2002, 11:1513-1530.

8. Furuta T, Ueda T, Aune G, Sarasin A, Kraemer KH, Pommier Y: Transcriptioncoupled nucleotide excision repair as a determinant of cisplatin sensitivity of human cells. Cancer Res 2002, 62:4899-4902.

9. Li Y, Liu Z, Liu H, Wang LE, Tan D, Ajani JA, Wei QY: ERCC1 and ERCC2 variants predict survival in gastric cancer patients. PLOS One 2013, 8:e71994.

10. Wang LE, Yin M, Dong Q, Stewart DJ, Merriman KW, Amos Cl, Spitz MR, Wei Q: DNA repair capacity in peripheral lymphocytes predicts survival of patients with non-small-cell lung cancer treated with first-line platinumbased chemotherapy. J Clin Oncol 2011, 29:4121-4128.

11. XU TP, Shen H, Liu LX, Shu YQ: Association of ERCC1-C118T and -C8092A polymorphisms with lung cancer risk and survival of advanced-stage nonsmall cell lung cancer patients receiving platinum-based chemotherapy: a pooled analysis based on 39 reports. Gene 2013, 526:265-274.

12. Kamikozuru H, Kuramochi H, Hayashi K, Nakajima G, Yamamoto M: ERCC1 codon 118 polymorphism is a useful prognostic marker in patients with pancreatic cancer treated with platinum-based chemotherapy. Int J Oncol 2008, 32:1091-1096.

13. Sereno M, Cejas P, Moreno V, Belda-Iniesta C, López R, Nistal M, Feliu J, De Castro Carpeño J: ERCC1 and topoisomerase I expression in small cell lung cancer: prognostic and predictive implications. Int J Oncol 2012, 40:2104-2110.

14. Su C, Zhou S, Zhang L, Ren S, Xu J, Zhang J, Lv M, Zhang J, Zhou C: ERCC1, RRM1 and BRCA1 mRNA expression levels and clinical outcome of advanced non-small cell lung cancer. Med Oncol 2011, 28:1411-1417.

15. Smith S, Su D, Rigault de la Longrais IA, Schwartz P, Puopolo M, Rutherford TJ, Mor G, Yu H, Katsaros D: ERCC1 genotype and phenotype in epithelial ovarian cancer identify patients likely to benefit from paclitaxel treatment in addition to platinum-based therapy. J Clin Oncol 2007, 25:5172-5179.

16. Bellmunt J, Paz-Ares L, Cuello M, Cecere FL, Albiol S, Guillem V, Gallardo E, Carles J, Mendez P, de la Cruz JJ, Taron M, Rosell R, Baselga J, Spanish Oncology Genitourinary Group: Gene expression of ERCC1 as a novel prognostic marker in advanced bladder cancer patients receiving cisplatin-based chemotherapy. Ann Oncol 2007, 18:522-528.

17. Shirota Y, Stoehlmacher J, Brabender J, Xiong YP, Uetake H, Danenberg KD, Groshen S, Tsao-Wei DD, Danenberg PV, Lenz HJ: ERCC1 and thymidylate synthase mRNA levels predict survival for colorectal cancer patients receiving combination oxaliplatin and fluorouracil chemotherapy. J Clin Oncol 2001, 19:4298-4304.

18. Matsubara J, Nishina T, Yamada Y, Moriwaki T, Shimoda T, Kajiwara T, Nakajima TE, Kato K, Hamaguchi T, Shimada Y, Okayama Y, Oka T, Shirao K: Impacts of excision repair cross-complementing gene 1 (ERCC1), dihydropyrimidine dehydrogenase, and epidermal growth factor receptor on the outcomes of patients with advanced gastric cancer. $\mathrm{Br} J$ Cancer 2008, 98:832-839.

19. Uchida K, Danenberg PV, Danenberg KD, Grem JL: Thymidylate synthase, dihydropyrimidine dehydrogenase, ERCC1, and thymidine phosphorylase gene expression in primary and metastatic gastrointestinal adenocarcinoma tissue in patients treated on a phase I trial of oxaliplatin and capecitabine. BMC Cancer 2008, 8:386

20. Krivak TC, Darcy KM, Tian C, Armstrong D, Baysal BE, Gallion H, Ambrosone CB, DeLoia JA, Gynecologic Oncology Group Phase III Trial: Relationship between ERCC1 polymorphisms, disease progression, and survival in the Gynecologic Oncology Group Phase III Trial of intraperitoneal versus intravenous cisplatin and paclitaxel for stage III epithelial ovarian cancer. J Clin Oncol 2008, 26:3598-3606.

21. Viguier J, Boige V, Miquel C, Pocard M, Giraudeau B, Sabourin JC, Ducreux M, Sarasin A, Praz F: ERCC1 codon 118 polymorphism is a predictive factor for the tumor response to oxaliplatin/5-fluorouracil combination chemotherapy in patients with advanced colorectal cancer. Clin Cancer Res 2005, 11:6212-6217. 
22. Takenaka T, Yano T, Kiyohara C, Miura N, Kouso H, Ohba T, Kometani T, Shoji F, Yoshino I, Maehara Y: Effects of excision repair cross-complementation group 1 (ERCC1) single nucleotide polymorphisms on the prognosis of non-small cell lung cancer patients. Lung Cancer 2010, 67:101-107.

23. De Castro G Jr, Pasini FS, Siqueira SA, Ferraz AR, Villar RC, Snitcovsky IM, Federico MH: ERCC1 protein, mRNA expression and T19007C polymorphism as prognostic markers in head and neck squamous cell carcinoma patients treated with surgery and adjuvant cisplatin-based chemoradiation. Oncol Rep 2001, 25:693-699.

24. Li C, Yin M, Wang LE, Amos Cl, Zhu D, Lee JE, Gershenwald JE, Grimm EA, Wei Q: Polymorphisms of nucleotide excision repair genes predict melanoma survival. J Invest Dermatol 2013, 133:1813-1821.

25. Quintela-Fandino M, Hitt R, Medina PP, Gamarra S, Manso L, Cortes-Funes H, Sanchez-Cespedes M: DNA-repair gene polymorphisms predict favorable clinical outcome among patients with advanced squamous cell carcinoma of the head and neck treated with cisplatin-based induction chemotherapy. J Clin Oncol 2006, 24:4333-4339.

26. Tiseo M, Bordi P, Bortesi B, Boni L, Boni C, Baldini E, Grossi F, Recchia F, Zanelli F, Fontanini G, Naldi N, Campanini N, Azzoni C, Bordi C, Ardizzoni A, Bio-FAST trial group: ERCC1/BRCA1 expression and gene polymorphisms as prognostic and predictive factors in advanced NSCLC treated with or without cisplatin. Br J Cancer 2013, 108:1695-1703.

27. Li Y, Gu S, Wu Q, Li Y, Fu X, Mao Y, Huang Y, Xie Y: No association of ERCC1 C8092A and T19007C polymorphisms to cancer risk: a metaanalysis. Eur J Hum Genet 2007, 15:967-973.

28. Peshkin BN, Alabek ML, Isaacs C: BRCA1/2 mutations and triple negative breast cancers. Breast Dis 2010, 32:25-33.

29. Metzger-Filho O, Tutt A, de Azambuja E, Saini KS, Viale G, Loi S, Bradbury I, Bliss JM, Azim HA Jr, Ellis P, Di Leo A, Baselga J, Sotiriou C, Piccart-Gebhart $\mathrm{M}$ : Dissecting the heterogeneity of triple-negative breast cancer. J Clin Oncol 2012, 30:1879-1887.

30. Lu X, Liu Y, Yu T, Xiao S, Bao X, Pan L, Zhu G, Cai Y, Liu Q, Jin C, Yang J, Wu $S, A n L$, van der Straaten T: ERCC1 and ERCC2 haplotype modulates induced BPDE-DNA adducts in primary cultured lymphocytes. PLoS One 2013, 8:e60006.

31. Palomba G, Pisano M, Cossu A, Budroni M, Dedola MF, Farris A, Contu A, Baldinu P, Tanda F, Palmieri G: Spectrum and prevalence of BRCA1 and BRCA2 germline mutations in Sardinian breast cancer patients through a hospital-based screening. Cancer 2005, 104:1172-1179.

32. Palomba G, Loi A, Uras A, Fancello P, Piras G, Gabbas A, Cossu A, Budroni M Contu A, Tanda F, Farris A, Orrù S, Floris C, Pisano M, Lovicu M, Santona MC, Landriscina G, Crisponi L, Palmieri G, Monne M: A role of BRCA1 and BRCA2 germline mutations in breast cancer susceptibility within Sardinian population. BMC Cancer 2009, 9:245.

33. Sobin LH, Gospodarowicz MK, Wittekind C: TNM Classification of Malignant Tumors. 7th edition. New York: John Wiley \& Sons; 2009.

34. Villarreal-Garza C, Khalaf D, Bouganim N, Clemons M, Peña-Curiel O, Baez-Revueltas B, Kiss A, Kassam F, Enright K, Verma S, Pritchard K, Myers J, Dent R: Platinum-based chemotherapy in triple-negative advanced breast cancer. Breast Cancer Res Treat 2014, 146:567-572.

35. Petrelli F, Coinu A, Borgonovo K, Cabiddu M, Ghilardi M, Lonati V, Barni S: The value of platinum agents as neoadjuvant chemotherapy in triplenegative breast cancers: a systematic review and meta-analysis. Breast Cancer Res Treat 2014, 144:223-232

36. Liu M, Mo QG, Wei CY, Qin QH, Huang Z, He J: Platinum-based chemotherapy in triple-negative breast cancer: a meta-analysis. Oncol Lett 2013, 5:983-991

37. Friedberg EC: How nucleotide excision repair protects against cancer. Nat Rev Cancer 2001, 1:22-33.

38. Liu YP, Ling Y, Qi QF, Zhang YP, Zhang CS, Zhu CT, Wang MH, Pan YD: The effects of ERCC1 expression levels on the chemosensitivity of gastric cancer cells to platinum agents and survival in gastric cancer patients treated with oxaliplatin-based adjuvant chemotherapy. Oncol Lett 2013, 5:935-942.

39. Arun B, Bayraktar S, Liu DD, Gutierrez Barrera AM, Atchley D, Pusztai L, Litton JK, Valero V, Meric-Bernstam F, Hortobagyi GN, Albarracin C: Response to neoadjuvant systemic therapy for breast cancer in BRCA mutation carriers and noncarriers: a single-institution experience. J Clin Oncol 2011, 29:3739-3746.

40. Alsop K, Fereday S, Meldrum C, de Fazio A, Emmanuel C, George J, Dobrovic A, Birrer MJ, Webb PM, Stewart C, Friedlander M, Fox S, Bowtell D,
Mitchell G: BRCA mutation frequency and patterns of treatment response in BRCA mutation-positive women with ovarian cancer: a report from the Australian Ovarian Cancer Study Group. J Clin Oncol 2012, 30:2654-2663.

41. Lips EH, Mulder L, Oonk A, van der Kolk LE, Hogervorst FB, Imholz AL, Wesseling J, Rodenhuis S, Nederlof PM: Triple-negative breast cancer: BRCAness and concordance of clinical features with BRCA1-mutation carriers. Br J Cancer 2013, 108:2172-2177.

doi:10.1186/s12967-014-0272-4

Cite this article as: Palomba et al:: ERCC1 polymorphisms as prognostic markers in T4 breast cancer patients treated with platinum-based chemotherapy. Journal of Translational Medicine 2014 12:272.

\section{Submit your next manuscript to BioMed Central and take full advantage of:}

- Convenient online submission

- Thorough peer review

- No space constraints or color figure charges

- Immediate publication on acceptance

- Inclusion in PubMed, CAS, Scopus and Google Scholar

- Research which is freely available for redistribution

Submit your manuscript at www.biomedcentral.com/submit
C) Biomed Central 